BEING THE JOURNAL OF THE BRITISH MEDICAI ASSOCIATION.

EDITED BY ANDREW WYNTER, M.D.

No. XXX.] LONDON : SATURDAY, JULY 25, 1857. [NEW SERIEs.

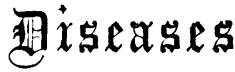

or

\section{SPECIAL OCCUPATIONS.}

\section{No. IV. \\ DISEASES OF MINERS OF ARKENDALE AND SWALEDALE.}

By Thomas Hayes Jackson, M.D., Darlington.

The miners, or "groovers", as they are termed, of Arkendale and Swaledale, reside in a wild romantic district, abounding with craggy rocks, wood, and water, hill and dale. In this picturesque scenery, the sublime, the terrific, and the magnificent, are intimately blended; and the sight will amply repay the tourist who is an admirer of nature, in its primeval beauty, unadorned by the hand of man. The two dales are situated about fourteen miles from Richmond, in Yorkshire; and this out of the way corner of the world has become more accessible since the railroad has been formed to the latter place, and a new road, following the windings of the river Swale, constructed as far as Reeth.

The average number of miners employed in the two districts of Arkendale and Swaledale is six or seven hundred. They are an industrious, sober, intelligent class of people, earning small wages, and therefore not having the means of obtaining the luxuries of life. This circumstance acts as a barrier against intemperance and other excesses. Their daily and nocturnal hours of toil are from five to seven hours, termed day-shifts and night-shifts. In many instances, from the nature of the strata, and the insufficiency of the "waygates" or driffs, as they term them, they are obliged to work in a constrained position, frequently in a damp and unhealthy atmosphere, so impure and deficient in oxygen, that two candles are obliged often to be placed in a half recumbent or dependent position to produce even a flickering ray of light. Death occasionally results from the foul air; which, in addition to the want of ablution or cleanliness of their persons, has a most detrimental effect on the health of the miners. Their skins absorb the lead; and the fine particles of dust containing lead ore which is raised when the miners are plying the pick, hack, or shovel, permeate the bronchi during respiration. Another exciting cause of ill health is their clothing, which consists of coarse flannel worn in contact with the skin, and covered with a loose harden jacket, or kitle. On their return to their domiciles, these garments are cast off, and hung up to dry : thus their dwellings are saturated with damp and noisome exhalations, which arise from the mud and moisture retained in their clothes. These exhalations are most detrimental to longevity; especially, as in many instances there are large families crowded into very small and ill ventilated cottages. In sorne instances the miners attain to a good old age; but their average duration of life is short, the mean duration being forty-five or fifty.

The smelters in this district, in consequence of the fumes arising from smelting the lead ore, being more deleterious to the organs of respiration, have a mean duration of life shorter by eight or ten years than that of the miner.

The rate of wages is small, the occupation being laborious. In mining phraseology the payment is made according to fathom-tale, wing-tale, or shift-tale. Fathom-tale, in length two yards, is paid according to the nature of the strata ; wing tale, according to the weight of ore ; shift-tale is paid by the hour, the average duration being six hours.

The dietary of the miners is meagre, consisting of tea, coffee, milk, cheese, potatoes, bread, and sometimes bacon. In 619 consequence of the low rate of wages, few or any of them are enabled to procure fresh animal food. Formerly, oatmeal was used extensively as an article of diet; at present, it is only used occasionally, being considered by the miners too heating; tea and coffee have in a great measure superseded it.

The miners of this part of the country, unfortunately, have no fund amongst themselves, to which they can appeal when suffering from accident or disease, nor do their employers encourage them to make any provision of the kind. The consequence is, that when a lead miner with a large family meets with misfortune, or has an accident in the mines, or is incapacitated by sickness and disease, he is under the necessity of locating himself in the poor-house to obtain sustenance and medical aid.

The miners commence to learn their calling at the age of 10 or 12 . Their first occupation is turning the windy king, a species of fan used to ventilate the mines. At the age of 14 they proceed, like their forefathers, to ply the pick, the hack, and the shovel. No doubt, the inhaling a vitiated atmosphere in their boyhood tends greatly to hasten premature disease and decadence. Thus, the worn-out man "shuffles off this mortal coil", and passes into the silent land, unheeded and uncared for by his employers, his place being supplied by new material, which treads in his predecessor's footsteps, until he in his turn is worn out and supplanted.

Fish cannot exist in the rills or small rivulets, into which the washings of the lead ore discharge themselves; though in the other mountain streams, in the immediate neighbourhood, unconnected with the mines, trout is to be found in great abundance.

\section{DISEASES.}

The diseases to which the miners are most liable, are congestion and inflammation of the lungs; acute and chronic bronchitis, termed by the miners belland; and phthisis, which often assumes the non-acute or chronic form. The sputa, in a great majority of these cases, have a sombre blue appearance, and sink in water. The treatment found most efficacious in the various bronchial affections of the miners, are emetics of ipecacuanha with antimony, sinapisms, and blisters; warm baths; warm stimulating expectorants, such as ammoniacum, squills, and lobelia inflata; and absolute rest from their occupation, more especially for those who have been working in the ill ventilated parts of the mines. Smoking prevails to an enormous extent amongst the miners, both young and old; some consider it most beneficial in relieving the difficulty of breathing, prevalent amongst the miners and smelters of the lead ore, by promoting expectoration. In some localities of this district scrofula prevails.

The females here, as in many other mountainous districts, are very subject to goitre, both the young and the old; and the males are not exempt from it. The females, when pregnant and suffering from immense goitre, are subject to have children born to them deaf, dumb, and idiotic; but when cured by the continued external application of iodine, the same females have borne children with their senses and intellects perfect.

In consequence of the coldness and dampness of the mines, combined with exhalations from drying their wet clothing in their dwellings, the miners suffer from muscular rheumatism, as well as from rheumatic fever. The treatment consists in administering acetate of potass, in combination with colchi. cum, opiate sudorifics at bedtime, and stimulating counterirritants.

The miners who toil in the many hives of industry which abound in Swaledale and Arkendale, are not liable either to paralysis, colica pictonum, or lead poisoning. The lead ore, being in the form of galena or sulphuret of lead, is less liable to become absorbed than the carbonate.

\section{ACCIDENTS.}

Considering the number of men employed, casualties occur less frequently than in the coal mines. The miners are liable to fracture of the lower extremities, and concussion of the brain and spinal cord, and lacerations of the scalp, from frag- 
ments of stone falling, and they are occasionally maimed from the wearing apparel becoming entangled in the machinery or rollers, which are used to crush the stones into small fragments, the lead ore being intimately blended with the limestone found in the mines. The accidents to which the miners are most obnoxious, are from blasting the rocks with gunpowder, termed "shots", producing (from excessive carelessness on the part of the miners) loss of vision, blueness, and disfiguration of the countenance. These unfortunate miners are thus branded for life.

They also suffer frequently from particles of stone and metal embedding themselves in the cornea, which, unless removed quickly by excision, produce inflammation of the eye and its appendages.

I cannot conclude without expressing my acknowledgments to Mr. McCollah, the surgeon resident on the spot, for the statistics embodied in this report.

\section{êllurstrations}

\section{HOSPITAL PRACTICE: METROPOLITAN AND PROTENCLAT.}

\section{N O R THA M T ON IN F I R A R Y. RESOLUTION OF ADIPOSE TUMOURS.}

By J. H. Webster, M.D., Physician to the Infirmary.

[Read before the South Midland Branch, May 21st, 1857.]

ADIPose tumours most frequently come under the province of the surgeon, the knife being the ultimatum whenever the number, size, disfigurement, or discomfort justifies operative interference; but in some few instances, as the subject of this paper, the rapidity of growth, the number of the parts affected, and a diffusedness of increase, admit of no strictly surgical treatment whatever, and any relief to the patient can be expected only from the most problematical and uncertain influence of internal, constitutional, alterative remedies.

The earliest stages of these growths are seldom noticed by the individual or his professional adviser, there being no pain or discomfort attending their first development, it often being a mere accident that draws attention to them; and when, from their increasing size, they force themselves into notice, the absence of local pain and constitutional disturbance, the uncertainty of their probable extent of growth, as sometimes also of their true character, and, when that is satisfactorily diagnosed, the knowledge that they seldom or never ulcerate, or assume the characters of malignant growths, all tend to dissuade from early and active operative interference.

During that period of expectancy as to the result, and irresolution on the part of both patient and practitioner as to the use of the knife, any simple and innocuous medical treatment, which may have been found by experience to have been beneficial in similar instances, may fairly be tried.

I adduce this case with the more confidence in the interest you will take in it from the fact that, whilst under treatment, the tumours rapidly decreased in size. Persistence in the remedy was attended with persistent reduction of their masses, until some of them entirely disappeared, as our worthy Chairman, who saw the case, as also the patient himself, now present, will testify; but becoming (as it might be expected) heartily sick of constantly taking medicine, the patient unwisely abandoned the remedy, and, shortly afterwards, the tumours began to increase, and have now attained nearly the same size as they were originally. This, to me, is a matter of regret, but it will corroborate in our minds the influence the drug must have had in their dispersion. The case is as follows:

CASE. Richard Wright, aged between 38 and 40 , formerly a post boy and farm labourer, but during the past eleven years a brewer's man, about five feet five inches in height, stout, and strongly built, of quasi-temperate habits, and always in the enjoyment of good health, was admitted to the Infirmary October 11th, 1856. A year and three quarters back a small pimple formed at the back of his right ear, which itching, he wounded the surface by scratching, when it rapidly increased to the size of a bantam's egg, becoming angry, hot, and painful, and accompanied with much constitutional disturbance. There being some obscure fluctuation in the tumour, it was opened by his medical attendant; some fluid escaped, and there was relief to the pain. The wound healed kindly, but the swelling became very hard and stony to the feel, and slowly increased in size, until it extended from the back of the right ear obliquely across towards the median line, and down as far as the fifth cervical vertebra, occupying, as it were, the exact site of the splenius capitis muscle.

About eighteen months afterwards a second tumour formed in the same region at the back of the left ear, increasing in a similar manner, but unattended with the stony hardness of the first and opposite one. Shortly afterwards, upon shaving, he discovered a swelling of the parts beneath the chin; this rapidly enlarged, giving the appearance of a substantial double chin.

Six weeks prior to admission, when trying on a pair of trousers, he discovered that the walls of the belly had become much larger and distended by four different swellings, two above and two below the umbilicus. Two other symmetrical formations were also observed in the pubic region, one on each side of the penis. These six last mentioned increased so rapidly as to reach their greatest size in the space of nine days.

The abdominal swellings were symmetrical in the supra and infraumbilical regions, and apparently developed in the cellular investments of the two recti muscles. The upper ones measured twelve inches laterally and horizontally, and ten inches vertically, occupying the whole space between the ensiform cartilage, false ribs, and the umbilicus. The two lower ones occupied the space from the umbilicus to within about two inches of the symphysis pubis.

There had been no treatment previous to his admission on October 11th, at which time all the tumours, though less indurated than formerly, were at their greatest size; the circumferential measurement of the abdomen then being thirtynine inches.

My colleague, Mr. Terry, under whom the case first came, tried alterative mercurial treatment, with iodine inunction, and moderate purgation, which was continued for a fortnight, when I was asked to see the case. Recollecting a very graphic description by Sir Benjamin Brodie, in his work on Pathology and Surgery, of a case nearly identical with this one, and the favourable issue of that case, I suggested the trial of the same simple remedy; namely, the liquor potassæ, largely diluted, in as full doses as could be taken without deranging the digestive function.

October 23rd. The patient was put upon half-drachm doses of the liquor potassæ in the compound infusion of linseed, thrice daily.

November 2nd. He thought himself improved, the tumours having a more doughy, spongy, semi-elastic feel. He had been passing, since taking the medicine, between seven and eight pints of urine in the twenty-four hours. He was ordered to take the medicine four times in the day.

November 6th. The liquor potassæ was increased to forty drops for a dose, four times daily.

November 8 th. He reported, that since taking the liquor potassæ all the tumours had become much softer, and the abdominal ones had much diminished in size, he being able now to button his trousers, which two days before he could not do by three to four inches. The urine amounted to from eight to ten pints. He was then made an out-patient, with instructions to continue the medicine in as full doses as he could take, without interfering with his health; but to reduce or intermit it whenever he found his urine becoming alkaline, having been furnished with litmus paper for ascertaining that point.

February 14, 1857. He had taken a cold, and was suffering from hoarseness of voice: he said he was quite well, saving the cold, but he looked pale, thin, and in impaired health, all the tumours were very much shrunk; that beneath the chin nearly gone. The posterior cervical ones had lost their prominency; and his aspect from behind was that of a man having merely a thick bull-set neck; the abdominal walls had so subsided that, in the erect posture, the line from the ensiform cartilage to the pubes was vertical, and the pubic swellings were quite gone. He had been taking thirty-five drops of liquor potassæ, thrice daily. The urine was much in excess. He was ordered to take, in addition, a drachm of compound tincture of cinchona three times daily. I understand that he persisted in the medicine for a fortnight, with continued improvement, and then abandoned it. Shortly afterwards the 